\title{
RE-EMERGENCE OF BOVINE HAEMORRHAGIC SEPTICAEMIA IN HUNGARY
}

\author{
Tibor MAGYAR ${ }^{1}$, Barbara UJVÁRI ${ }^{1}$, Levente SZEREDI $^{2}$, Norbert VIRSINGER ${ }^{3}$, \\ Ervin AlBERT ${ }^{4,5}$, Zoltán NÉMET $^{4}$, Edit CSUKA $^{4}$ and Imre BIKSI ${ }^{4 *}$ \\ ${ }^{1}$ Institute for Veterinary Medical Research, Centre for Agricultural Research, Hungarian \\ Academy of Sciences, Budapest, Hungary; ${ }^{2}$ Veterinary Diagnostic Directorate, Central \\ Agriculture Office, Budapest, Hungary; ${ }^{3}$ Private Veterinarian, Szendehely, Hungary; \\ ${ }^{4}$ Department and Clinic for Production Animals, University of Veterinary Medicine, \\ H-2225 Üllö, Hungary; ${ }^{5}$ MTA-SZIE Large Animal Clinical Research Group, Üllő, Hungary
}

(Received 4 October 2016; accepted 2 November 2016)

This paper reports an outbreak of haemorrhagic septicaemia caused by Pasteurella multocida B:2 in beef calves, a disease that has not been described in the Hungarian literature since 1943, and has not been reported to the World Organisation For Animal Health (OIE) since 1970. Acute haemorrhagic septicaemia was confirmed in beef calves on one small farm, and was suspected on two further nearby holdings with concomitant unexplained losses. The source of the infection could not be determined. Apart from a short duration of depression and loss of appetite, the affected calves developed characteristic distal limb oedema. Gross findings in two calves submitted for laboratory examinations included subcutaneous oedema and haemorrhages on serous membranes, and in one case severe pharyngeal lymph node enlargement was observed. Histological examinations revealed lesions characteristic of septicaemia. Moderate to large amounts of Pasteurella antigens were detected in all organs tested by immunohistochemistry. Two isolates of $P$. multocida (Pm240, Pm241) were cultured from these cases and examined in detail. These were identified as P. multocida ssp. multocida biovar 3. Both were toxA negative and belonged to serotype B:2. Multilocus sequence typing was used to assign these to a new sequence type (ST64) that is closely related to other haemorrhagic septicaemia causing strains of $P$. multocida regardless of the host.

Key words: Pasteurella multocida, capsular type B, haemorrhagic septicaemia, beef cattle, histopathology, immunohistochemistry, multilocus sequence typing

Haemorrhagic septicaemia (HS) is an acute, frequently fatal disease of cattle and buffaloes in tropical regions of the world, especially in Africa and Asia. HS is caused by certain serotypes of Pasteurella multocida, B:2 being the dominant serotype in Asia, and E:2 in African countries. HS related cases have occa-

*Corresponding author; E-mail: biksi.imre@univet.hu; Phone: 0036 (29) 521-350 
sionally been reported from Europe in cattle, swine and wild ruminants (Aalbek et al., 1999; Soike and Schulze, 2011; Cardoso-Toset et al., 2013).

Occurrence of bovine HS in Hungary was last mentioned in the relevant literature in 1943 (Sziráky, 1943), and was last reported to the OIE in 1970 (https://web.oie.int/hs2/sit_mald_freq pl.asp?c_cont=4\&c_mald=39); however, no details of this report are available now. Since then, the country has been considered free of the disease as neither HS suspect cases have been observed nor $P$. multocida serotype B:2 has been isolated. Recently, an outbreak of P. multocida B:2 associated generalised pasteurellosis has been reported in backyard pigs in Hungary (Ujvári et al., 2015) that indicated the presence of the pathogen in the country, although the source of the infection could not be established.

In this paper we report the occurrence of bovine HS caused by $P$. multocida serotype B:2 in Hungary, indicating the local re-emergence of this disease.

\section{Materials and methods}

Cases

Two dead calves of approximately 6 months of age were submitted from a small beef herd in northern Hungary to the Diagnostic Laboratory of the Department and Clinic of Production Animal Medicine at the end of July 2016. These were the last of nine calves that had died during a three-week period from a group of 24 animals of approximately 150-200 kg body weight. All calves had been born and raised in this herd. All succumbed animals showed a short period of lethargy, inappetence, respiratory distress, and marked subcutaneous oedema of the distal extremities, especially under the hock. Calves died within 8-12 h after showing the first clinical signs. Rectal temperature was not measured in any of the cases, and the other seven dead calves were not submitted to the laboratory for diagnostic examinations. This free-range herd consists of 50 cows and their calves, rotationally grazing pastures mingled with woods. Drinking water was provided from a stream frequented also by local wildlife as no fence separated the pastures. The herd is bovine viral diarrhoea virus positive, unvaccinated, with no clinical signs attributable to this disease.

We visited the farm to gather further information on the circumstances of this outbreak. An interview with the owner revealed that two other farms, about five kilometres away, experienced similar losses in the same period. Rapid death with short clinical illness, respiratory distress, and marked limb oedema characterised these cases as well. Two out of three beef calves at the second site, and one out of six calves on the third site died concurrently with the outbreak described here. None of these animals were submitted for diagnostic examinations. Direct contact (animal movement) reportedly did not happen between these sites, but indirect contact by fomites was likely, as the owners frequently visited each 
other. There is no information on the involvement of pigs on any of the sites; however, one neighbour to site 2 experienced severe, unexplained losses in a sheep flock beforehand - unfortunately, diagnostic examinations were not performed on those carcasses either. The area of the recently reported Pasteurella multocida B:2 outbreak in backyard pigs (Ujvári et al., 2015) is about $130 \mathrm{~km}$ to the west from the farms in this report, with no known contact between these sites.

\section{Gross pathological, histopathological and immunohistochemical examinations}

Dissection of the calves was done according to standard procedures at the Laboratory. Tissue samples from the spleen, lymph nodes, lungs and brain were collected and fixed in 10\% neutral buffered formalin (Reanal Zrt., Budapest). Due to the advanced autolytic status of Case 1, only samples from Case 2 were processed further. These were embedded in paraffin, sectioned at $4 \mu \mathrm{m}$, and stained with haematoxylin and eosin (HE). Immunohistochemistry (IHC) was used on tissue sections from Case 2 to detect Pasteurella antigens as reported previously (Szeredi et al., 2010; Ujvári et al., 2015).

\section{Bacteriological examinations}

Samples from the spleen and brain (Case 1) and spleen, brain and peripharyngeal lymph node (Case 2) were submitted to routine aerobic bacteriological examination. Samples from these organs were streaked on Columbia agar (Biolab Zrt., Hungary) plates supplemented with 5\% sheep blood. Plates were incubated at $37^{\circ} \mathrm{C}$ for $24 \mathrm{~h}$. Primary identification of cultured bacteria was based on colony morphology and biochemical tests.

Biovar determination was based on ornithine decarboxylase activity and carbohydrate fermentation patterns. Production of ornithine decarboxylase was determined in the presence of $1 \%$ L-ornithine. Lactose, maltose, arabinose, trehalose, xylose, dulcitol and sorbitol tests were performed using sterile solutions of sugars or alcohols, peptone water, and bromothymol blue in a final concentration of $1 \%$, with the test tubes incubated at $37^{\circ} \mathrm{C}$ for $24 \mathrm{~h}$.

Presumptive isolate identification was confirmed using a species-specific PCR assay (Townsend et al., 1998). Combinations of oligonucleotide primers were used for amplification of $k m t 1$ (species identification), toxA (P. multocida toxin) and hyaC-hyaD (capsular type A) sequences in the same reaction (Gautam et al., 2004; Register and DeJong, 2006). With the exception of serogroup A, capsular type was identified using a multiplex PCR method as described previously (Townsend et al., 2001). The somatic serotype was determined using a multiplex PCR assay (Harper et al., 2014). Classical serotyping using agar gel diffusion precipitation test was also carried out (Heddleston et al., 1972). 

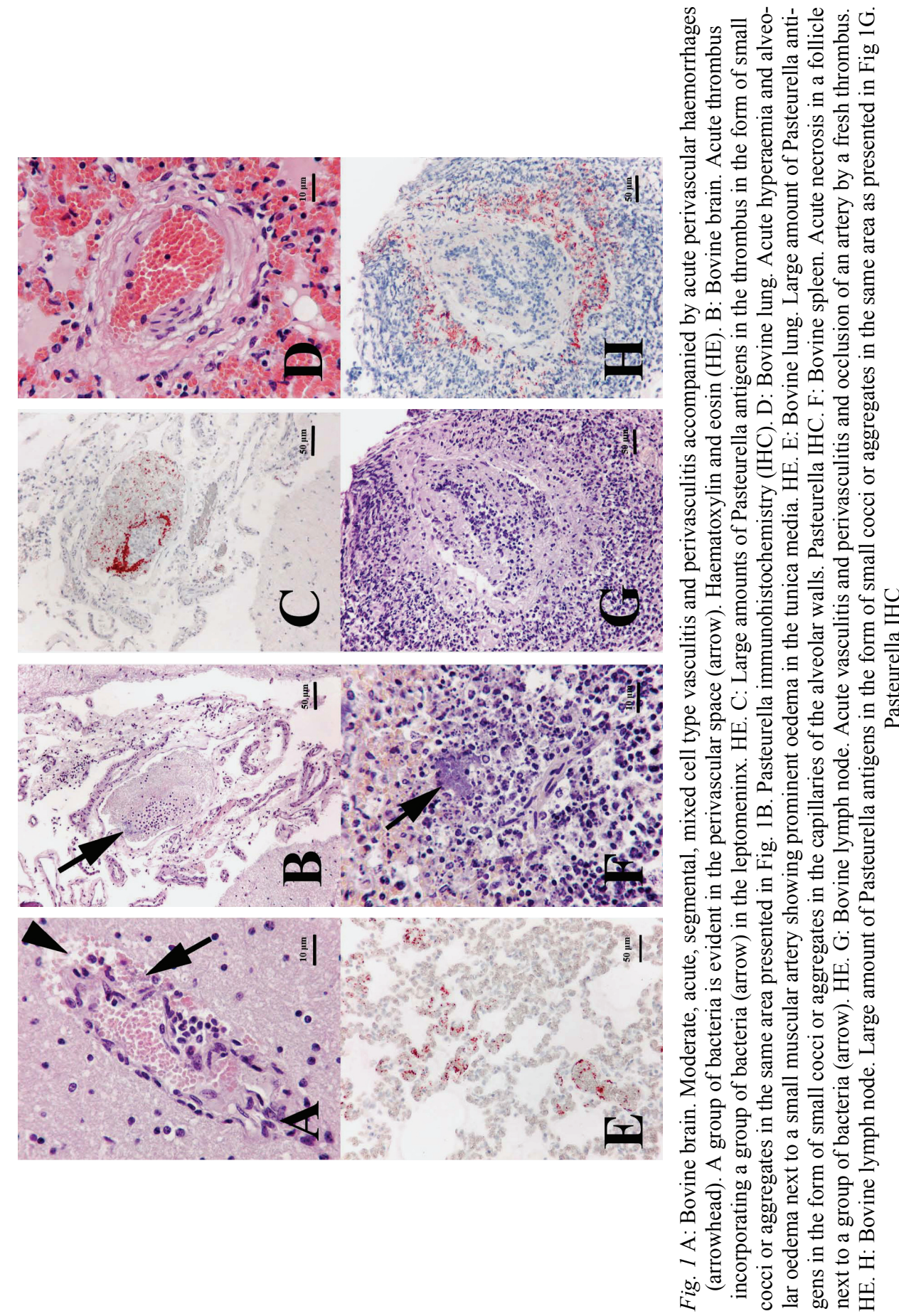


\section{DNA preparation}

A loopful of cultured bacterial growth was suspended in $50 \mu \mathrm{L}$ sterile double-distilled water and heated in a thermal cycler at $99{ }^{\circ} \mathrm{C}$ for $20 \mathrm{~min}$. Cellular debris was pelleted by centrifugation and the supernatant used as the DNA template for PCR amplification.

\section{Multilocus sequence typing (MLST)}

The genetic relationship of $P$. multocida Pm240 and Pm241 was analysed by sequencing seven housekeeping genes. MLST was performed as described by Davies et al. (2004). Purification and sequencing of PCR products from both strands were performed by Macrogen Europe (Amsterdam, The Netherlands). Nucleotide sequences were aligned and compared using BioEdit software (version 7.2.3) (Hall, 1999). Sequence data was analysed using a web-based MLST method (http://cge.cbs.dtu.dk/services/MLST/). Sequence types and allelic profiles were submitted to the $P$. multocida multihost MLST database (http://pubmlst. org/pmultocida_multihost/). A neighbour-joining tree was drawn from the concatenated sequences (3990 bp) using MEGA 6 (Tamura et al., 2013).

\section{Results}

Dissection of the first calf (Case 1) revealed marked autolysis, moderate to good condition, severe serosanguinous fluid accumulation in the submandibular, lower neck and brisket regions, scattered fresh petechial haemorrhages throughout serous membranes (peritoneum, mesentery, pericardium), and mild diffuse splenomegaly. The second calf (Case 2), received five days later, was in good state of nourishment, had moderate oedema in the subcutis and in the intermuscular connective tissues with few petechial haemorrhages in the submandibular and ventral neck regions, scattered fresh petechial haemorrhages throughout the serous membranes, a very severe submandibular and peripharyngeal lymph node enlargement, severe acute diffuse lung oedema, and mild diffuse meningeal congestion. Mild congestion of the kidneys and liver was also noted.

Microscopic examination revealed moderate, acute, mixed cell type vasculitis and perivasculitis, leukostasis, occasional presence of acute fibrin thrombi or acute thrombi, and acute haemorrhages in the brain and leptomeninx (Fig. 1A and B). In the lungs, acute hyperaemia, alveolar oedema and emphysema was found, and several small muscular arteries presented prominent oedema in the tunica media (Fig. 1D). Intravascular bacterial emboli and acute fibrin thrombi were also frequently observed in the lungs. Acute multifocal necrosis was evident in the follicles of spleen and lymph node, accompanied by the presence of groups of bacteria (Fig. 1F). Additionally, acute serous lymphadenitis and vascu- 
litis and the presence of acute thrombi incorporating also groups of bacteria were detected in a lymph node (Fig. 1G). Moderate to large amounts of Pasteurella antigens were detected in all organs tested. The bacterium was located mostly extracellularly in the lumen of blood vessels in the form of cocci in groups or as aggregates (Fig. 1C, E and H). Pasteurella antigens were rarely detected in the cytoplasm of different cell types including macrophages, endothelial cells and neutrophil granulocytes in the form of cocci but also as aggregates (Fig. 1H).

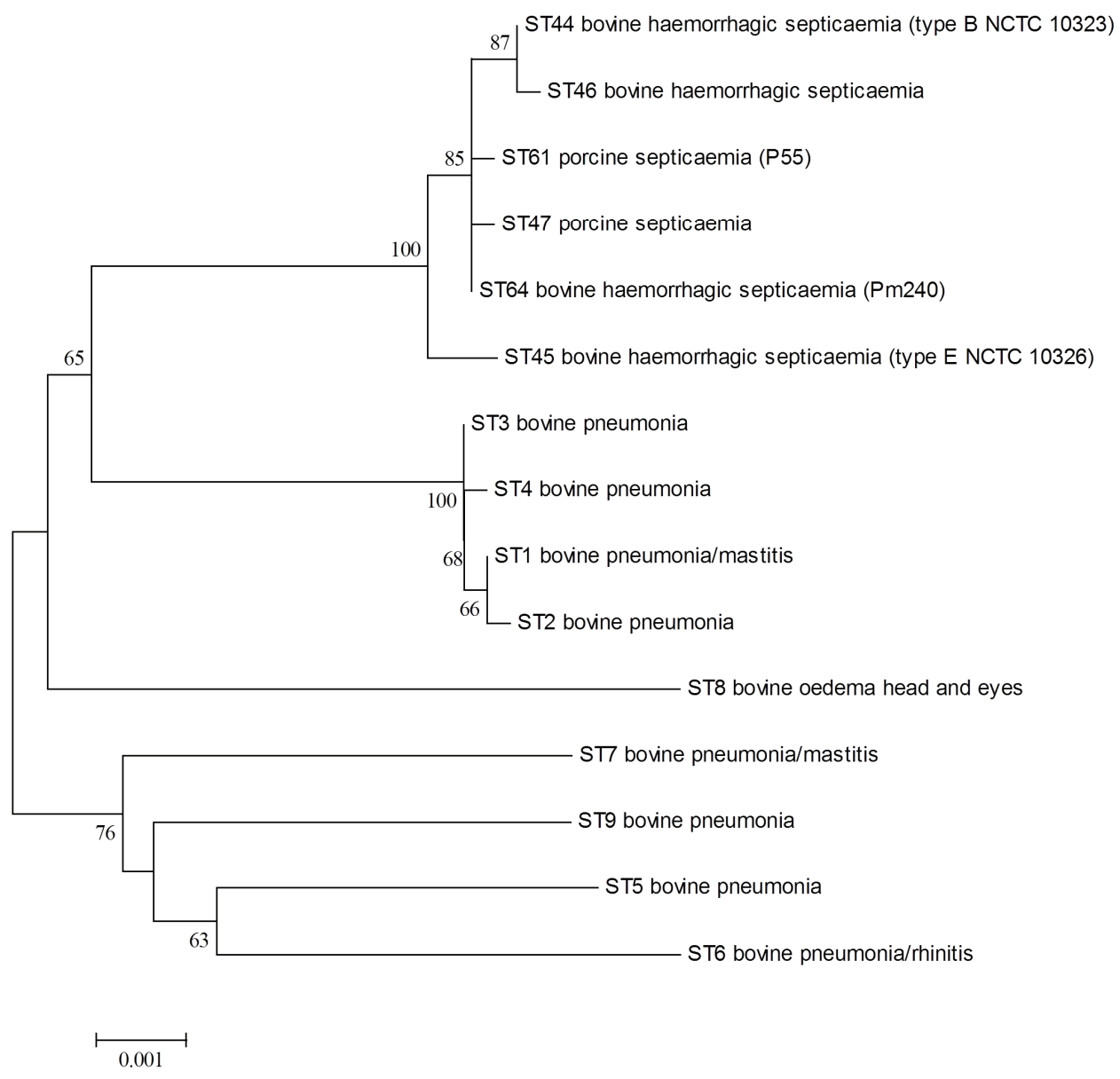

Fig. 2. Evolutionary relationships of Pasteurella multocida strains from various disease phenotypes. Evolutionary history was inferred using the neighbour-joining method. The percentage of replicate trees in which the associated taxa clustered together in the bootstrap test (1000 replicates) are shown next to the branches. The evolutionary distances were computed using the maximum composite likelihood method and are expressed in units of the number of base substitutions per site. Evolutionary analyses were conducted in MEGA6 
Heavy growth of $P$. multocida in nearly pure culture was detected in both cases from each organ sampled. One strain, isolated from the spleen in both cases, was submitted for further identification and molecular biological characterisation.

These two isolates from the present outbreak (designated $P$. multocida Pm240 and Pm241) were identified as $P$. multocida. They showed ornithine decarboxylase activity and fermented xylose and sorbitol but did not produce acid from arabinose, maltose, lactose, trehalose and dulcitol. Based on fermentation abilities, the strains were assigned to biovar 3, and serotyping determined these isolates as B:2. The tox $A$ gene was not detected in either of the isolates.

MLST analysis of concatenated sequences from the serotype B:2 strains (Pm240, Pm241) demonstrated a new sequence type (ST64), with allelic profile adk 26, aroA 28, deoD 23, g6pd 23, gdhA 6, mdh 22 and pgi 25. ST64 has one different locus compared with ST61 (aroA), ST45 (deoD), and ST47 (gdhA). Furthermore, this sequence type is a double locus variant of ST44 (aroA and $g d h$ ) and has three different loci compared with ST46 (aroA, g6pd and gdhA). Comparison to isolates in the multi-host MLST database revealed a clearly separated cluster of HS-causing sequence types (STs) with high bootstrap support values. A neighbour-joining dendrogram was constructed to represent the genetic distance of these closely related STs (Fig. 2).

\section{Discussion}

The cause of sudden losses in a small Hungarian beef herd was determined as acute septicaemia caused by $P$. multocida ssp. multocida biovar 3, serotype $\mathrm{B}: 2$. This disease had been last described in the Hungarian literature more than 70 years ago, and was last reported to the OIE from Hungary almost 50 years ago, so the re-emergence of this pathogen was somewhat surprising, but not completely unexpected. There are some recent reports from Europe on the occurrence of HS in cattle, wild ruminants and swine (Soike and Schulze, 2011). The source of the infection in this outbreak could not be determined with certainty. However, as the affected herd was not isolated from local wildlife, even sharing the water source, it is possible that the source of the infection was diseased wild ruminants or feral hogs. According to the National Game Management Database the number of wild ruminants and feral hogs has significantly increased in the last 10 years (http://ova.info.hu/index-en.html), which might favour the contact between domestic and wild animals. Screening livestock and wildlife (hunted or perished) for the presence of $P$. multocida serotype B:2 would be advisable in the region to estimate the prevalence of carrier state. Weather conditions have been repeatedly mentioned to play an important role in HS outbreaks (Murthy and Kaushik, 1965; Soike and Schulze, 2011; Ujvári et al., 2016). Adverse weather 
conditions could have played a role in this case as well. In the middle of July 2016 a large cold weather front reached Hungary. The temperature dropped from $36{ }^{\circ} \mathrm{C}$ to $26^{\circ} \mathrm{C}$ in a few hours, the wind gust exceeded $100 \mathrm{~km} / \mathrm{h}$, and the precipitation reached $140 \mathrm{~mm}$ in the region for 48 hours (http://www.met.hu/ismerettar/meteorologiai_hirek/index.php?id=1541\&m=2\&hir=2016._eddigi_legviharos abb_ejszakaja).

MLST analysis revealed that our $P$. multocida $\mathrm{B}: 2$ isolates represented a new sequence type (ST64) showing close relationship with other HS-causing strains of $P$. multocida independently of the host of origin. This finding further confirms that capsular type B strains form a highly homogeneous, distinct phylogenic group within P. multocida. Although strain P55 that we isolated from swine (Ujvári et al., 2015) represents a distinct sequence type (ST61), the difference between sequence types ST64 and ST61 is rather small, therefore strain P55 cannot be completely ruled out as a possible source of infection. However, it is still an open question how the pathogen has entered this region, as a result of which Central Europe has become affected by the disease. Due to the accelerated movement of goods and people, the bacterium might have come from greater distances as well.

Although no serotyping had been available at the time of the last reported HS incidence in cattle and buffaloes in Hungary (Sziráky, 1943), the obvious differences between $P$. multocida isolates recovered from those cases and from other forms of pasteurellosis (Csontos and Derzsy, 1943), together with the typical clinical signs and pathological findings, makes it certain that genuine HS occurred in the country. We can conclude, therefore, that after many years, haemorrhagic septicaemia should be added again to the list of acute fatal systemic diseases of cattle in Hungary. Further occurrence of the condition in cattle or in pigs can be anticipated, which underlines the importance to perform detailed typing of P. multocida isolates recovered from cases of septicaemia.

\section{Acknowledgement}

The technical assistance of É. Hegedủs and K. Oryszcsák is gratefully acknowledged.

\section{References}

Aalbek, B., Eriksen, L., Rimler, R. B., Leifsson, P. S., Christiansen, A. T. and Eriksen, E. (1999): Typing of Pasteurella multocida from haemorrhagic septicaemia in Danish fallow deer (Dama dama). APMIS 107, 913-920.

Cardoso-Toset, F., Gómez-Laguna, J., Callejo, M., Vela, A. I., Carrasco, L., FernándezGarayzábal, J. F., Maldonado, A. and Luque, I. (2013): Septicaemic pasteurellosis in freerange pigs associated with an unusual biovar 13 of Pasteurella multocida. Vet. Microbiol. 167, 690-694. 
Csontos, J. and Derzsy, D. (1943): Immunobiological characteristics of Pasteurella strains [in Hungarian]. Állatorvosi Lapok 66, 73-75.

Davies, R. L., MacCorquodale, R. and Reilly, S. (2004): Characterisation of bovine strains of Pasteurella multocida and comparison with isolates of avian, ovine and porcine origin. Vet. Microbiol. 99, 145-158.

Gautam, R., Kumar, A. A., Singh, V. P., Singh, Vijendra P., Dutta, T. K. and Shivachandra, S. B. (2004): Specific identification of Pasteurella multocida serogroup-A isolates by PCR assay. Res. Vet. Sci. 76, 179-185.

Hall, T. A. (1999): BioEdit: a user friendly biological sequence alignment editor and analysis program for Windows 95/98/NT. Nucl. Acids Symp. Series 41, 95-98.

Harper, M., John, M., Turni, C., Edmunds, M., St Michael, F., Adler, B., Blackall, P. J., Cox, A. D. and Boyce, J. D. (2014): Development of a rapid multiplex PCR to genotype Pasteurella multocida strains using the lipopolysaccharide outer core biosynthesis locus. J. Clin. Microbiol. 53, 477-485.

Heddleston, K. L., Gallagher, J. E. and Rebers, P. A. (1972): Fowl Cholera: Gel diffusion precipitin test for serotyping Pasteurella multocida from avian species. Avian Dis. 16, 925-936.

Murthy, D. K. and Kaushik, R. K. (1965): Studies on an outbreak of acute swine pasteurellosis due to Pasteurella multocida type B (Carter, 1955). Vet. Rec. 77, 411-416.

Register, K. B. and DeJong, K. D. (2006): Analytical verification of a multiplex PCR for identification of Bordetella bronchiseptica and Pasteurella multocida from swine. Vet. Microbiol. 117, 201-210.

Soike, D. and Schulze, C. (2011): Acute pasteurellosis in fallow deer, cattle and pigs in a region of Eastern Germany. Berl. Munch. Tierarztl. Wochenschr. 125, 122-128.

Szeredi, L., Jánosi, Sz. and Pálfi, V. (2010): Microbiological and pathological examinations of fatal calf pneumonia cases induced by bacterial and viral respiratory pathogens. Acta Vet. Hung. 58, 341-356.

Sziráky, G. (1943): Pasteurellosis from the administrative point of view [in Hungarian]. Állatorvosi Lapok 66, 67-68.

Tamura, K., Stecher, G., Peterson, D., Filipski, A. and Kumar, S. (2013): MEGA6: Molecular Evolutionary Genetics Analysis version 6.0. Molecular Biology and Evolution 30, 2725-2729.

Townsend, K. M., Boyce, J. D., Chung, J. Y., Frost, A. J. and Adler, B. (2001): Genetic organization of Pasteurella multocida cap loci and development of a multiplex capsular PCR typing system. J. Clin. Microbiol. 39, 924-929.

Townsend, K. M., Frost, A. J., Lee, C. W., Papadimitriou, J. M. and Dawkins, H. J. S. (1998): Development of PCR assays for species- and type-specific identification of Pasteurella multocida isolates. J. Clin. Microbiol. 36, 1096-1100.

Ujvári, B., Szeredi, L., Pertl, L., Tóth, G., Erdélyi, K., Jánosi, Sz., Molnár, T. and Magyar, T. (2015): First detection of Pasteurella multocida type B:2 in Hungary associated with systemic pasteurellosis in backyard pigs. Acta Vet. Hung. 63, 141-156.

Ujvári, B., Szeredi, L., Pertl, L., Tóth, G., Erdélyi, K., Jánosi, Sz., Molnár, T. and Magyar, T. (2016): Disease caused by Pasteurella multocida type B:2 in pigs. Review of the literature and case report [in Hungarian, with English abstract]. Magy. Allatorvosok 138, 333-346. 